\title{
Evaluación fisicoquímica y organoléptica de café (Coffea arabica L.) fermentado con rumen y Saccharomyces cereviciae a diferente temperatura
}

\section{Physicochemical and organoleptic characteristics of coffee (Coffea arabica L.) fermented with Saccharomyces cerevisiae and rumen at different temperatures}

\author{
Segundo Víctor olivares Muñoz; ${ }^{2}$ Meregildo Silva Ramírez²; Nelly Ocampo cachay ${ }^{3}$
}

\section{RESUMEN}

La investigación tuvo por objetivo evaluar las características fisicoquímicas y organolépticas de café (Coffea arabica L.) fermentado con Saccharomyces cerevisiae y rumen a diferente temperatura; para lo cual se estableció un diseño bi-factorial 3A x 3B, el factor A fue la relación porcentaje de $S$. cerevisiae - porcentaje de rumen ( $0 \%: 0 \% ; 0 \%: 10 \% ; 1 \%: 10 \%)$ y el factor B fue la temperatura de fermentación $\left(25^{\circ} \mathrm{C}, 30^{\circ} \mathrm{C}\right.$ y $\left.35^{\circ} \mathrm{C}\right)$; se procedió al beneficio del café cerezo en el distrito de Limabamba ubicado a 1230 m.s.n.m; con procedimientos de acuerdo a Norma Técnica Colombiana, la fermentación se llevó acabo en un prototipo de biodigestor; de acuerdo al análisis estadístico y prueba de Friedman; se determinó la obtención de café caracterizado con perfil organoléptico "Mucha caña, frutos secos, ciruelas, manzana roja, frambuesa" y calificación hedónica "Muy bueno", para aroma, sabor, acidez, textura, cuerpo y defectos de taza; obtenido en un tiempo de fermentación de 12 horas; a $30^{\circ} \mathrm{C}$, con adición de $1 \%$ de levadura $-10 \%$ de rumen de ganado vacuno (T8) y 3\% de agua, a una altitud de 1230 m.s.n.m; con un $\mathrm{pH}$ 5.02; asimismo en el proceso de fermentación se observó la variación del pH de 5,1 a 3,86, los sólidos solubles totales de 4,3 a $5,9^{\circ} \mathrm{Brix}$, la acidez titulable de 1028 a $3409 \mathrm{mg} \mathrm{de} \mathrm{CaCO}_{3}$

Palabras clave: Fermentación, S. cerevisiae, rumen, temperatura, evaluación fisicoquímica y organoléptica

\begin{abstract}
The objective of the research was to evaluate the physicochemical and organoleptic characteristics of coffee (Coffea arabica L.) fermented with Saccharomyces cerevisiae and rumen at different temperatures; for which a bifactorial design $3 \mathrm{~A} \times 3 \mathrm{~B}$ was established, factor $\mathrm{A}$ was the percentage ratio of $\mathrm{S}$. cerevisiae - percentage of rumen ( $0 \%: 0 \%, 0 \%: 10 \%, 1 \%: 10 \%)$ and the factor $\mathrm{B}$ was the fermentation temperature $\left(25^{\circ} \mathrm{C}, 30^{\circ} \mathrm{C}\right.$ and $\left.35^{\circ} \mathrm{C}\right)$; the benefit of the cherry coffee in the district of Limabamba located at 1230 m.n.m; With procedures according to Colombian Technical Standard, the fermentation was carried out in a biodigester prototype; according to the statistical analysis and Friedman's test; it was determined the obtaining of coffee characterized with organoleptic profile "Mucha cane, nuts, plums, red apple, raspberry" and hedonic rating "Very good", for aroma, flavor, acidity, texture, body and cup defects; obtained in a fermentation time of 12 hours; at $30^{\circ} \mathrm{C}$, with addition of $1 \%$ yeast $10 \%$ rumen of cattle (T8) and $3 \%$ of water, at an altitude of 1230 m.s. with a pH 5.02 ; Likewise in the fermentation process, the $\mathrm{pH}$ variation was observed from 5.1 to 3.86 , the total soluble solids from 4.3 to $5.9^{\circ} \mathrm{Brix}$, the titratable acidity from 1028 to $3409 \mathrm{mg}$ of $\mathrm{CaCO} 3$
\end{abstract}

Keyword: Fermentation, S. cerevisiae, rumen, physicochemical and organoleptic evaluation temperature

\footnotetext{
${ }^{1}$ Ingeniero agroindustrial, Profesor auxiliar a Tiempo completo de la Facultad de Ingeniería y Ciencias agrarias de la Universidad Nacional Toribio Rodríguez de Mendoza de Amazonas; especialista en docencia y gestión universitaria, Universidad Nacional Pedro Ruiz Gallo. Correo electrónico: sv.olivares@gmail.com

${ }^{2}$ Ingeniero mecánico, Profesor asociado de la Facultad de Ingeniería y Ciencias agrarias de la Universidad Nacional Toribio Rodríguez de Mendoza de Amazonas. Correo electrónico: meregildo.silva@utrm.edu.pe

${ }^{3}$ Estudiante de Ingeniería agroindustrial de la Facultad de Ingeniería y Ciencias agrarias de la Universidad Nacional Toribio Rodríguez de

Mendoza de Amazonas. Correo electrónico: nellyo@gmail.com
} 


\section{INTRODUCCIÓN}

De acuerdo a la Organización Internacional del café, (OIC), la industria del café genera cada año más de 120 millones de empleos a nivel mundial y ventas anuales mayores a los 90 mil millones de dólares (más de 65 mil millones de euros) a nivel mundial. (Queirolo, 2010).

El cafeto es la planta estimulante más difundida en el mundo, ocupa grandes áreas de América y África. La actividad cafetalera en el Perú involucra a más de 2 millones de peruanos. Esto se da toda vez que nuestro café se produce en 338 distritos rurales, de 68 provincias, ubicadas en 12 regiones. (Misti, 2017); es la principal actividad agrícola lícita en los valles de la selva del país (los mayores rendimientos se obtienen en regiones como Amazonas, San Martín y Cajamarca), se posesiona como el cultivo alternativo más importante frente a la coca (Agrobanco, 2007).

En marzo 2017, la producción de café registró 20 mil 19 toneladas y se incrementó en $21,4 \%$ respecto al mes de marzo 2016; en regiones como San Martín (41,5\%), Junín (34,2\%) y Cajamarca $(13,6 \%$ ) que en conjunto concentraron el $77,1 \%$ de la producción nacional. Asimismo, aumentó en los departamentos de Ayacucho (116,3\%), Huánuco (11,7\%), Pasco (10,3\%), Madre de Dios (9,9\%) y La Libertad $(1,1 \%)$. Por el contrario, fue menor en Ucayali ($39,1 \%)$, Amazonas $(-27,2 \%)$ y Cusco $(-7,0 \%)$. (Inei, 2017).

De acuerdo a lo mencionado el café es un producto de alta importancia para la economía nacional; sin embargo para su desarrollo y mejor valoración en el mercado mundial necesita la estandarización de la calidad sensorial, ya que de ello depende el precio de venta que en la actualidad variable, en la región Amazonas el precio va desde 2 a 10 soles.

Desde el punto de vista agroindustrial existiría un problema tecnológico en el proceso de beneficio en la fermentación, que es punto crítico ya que este proceso determina la calidad y las ventajas competitivas y comparativas del café. En la actualidad el proceso de fermentación; de acuerdo a la inspección in situ; no es controlada, es empírica.

En lo referente a la fermentación del café hasta la fecha diversos investigadores han tratado de dar respuesta a las diversas problemáticas que tiene el desarrollo de la caficultura y la mejora permanente de la calidad del café; es así que se realizó el registro durante 80 horas continuas del comportamiento de algunas variables $\left(\mathrm{pH}, \mathrm{T}^{\mathrm{o}}\right.$ ambiente, $\mathrm{H}^{\mathrm{o}}$ relativa, grados ${ }^{\circ}$ Brix) asociadas al proceso de fermentación de café Coffe arabica y se determinó como el tiempo de fermentación afecta la calidad de la bebida de café. (López, et al., 2015).

Se determinó el efecto de la fermentación aerobia del grano despulpado de café orgánico, en el desarrollo de características sensoriales de la bebida, logra la producción de compuestos de aroma y sabor. (Arcos, 2017).

Se identificaron y cuantificaron las bacterias y levaduras del mucílago de Coffea arabica, fresco y fermentado hasta por 74 horas, a temperatura ambiente y en sistemas abiertos. Se hallaron diversos microrganismos en el mucílago de café sin fermentar; los mayores recuentos se encontraron en el mucílago de café obtenido de frutos maduros y granos seleccionados. (Puerta, Marín, \& Osorio, 2012).

Se cuantificaron concentraciones de azúcares totales, azúcares reductores, acidez y etanol del mucílago de café durante $74 \mathrm{~h}$ de fermentación a temperatura ambiente. Los cambios en las concentraciones de azúcares, ácidos y etanol en la fermentación del mucílago variaron con el tiempo. (Puerta G. I., 2013).

Se logró determinar el tiempo de duración del proceso para situar el café en un $\mathrm{pH}$ ideal de 3,5 teniendo en cuenta una temperatura ambiente de $20^{\circ}$ $\mathrm{C}$ y una altura que oscila entre los $1.470-1.500$ metros sobre el nivel del mar. (Cárdenas \& Pardo, 2014).

Se demostró que a partir de un 2,5\% de café cosechado verde, ya sea procesado por desmucilaginado mecánico o por fermentación natural, se rechazan desde el $30 \%$ de las tazas por defectos, sucio, fermento, tinker, tierra y sabores desagradables y se disminuye en $7 \%$ el rendimiento del pergamino en relación con el café maduro.. (Puerta G. I., 2000).

En Cenicafé, se desarrolló la escala para calificar el aroma del café molido, el aroma de la bebida, la acidez, el amargo, el cuerpo y la impresión global (sabor) del café, basados en la descripción y vocabulario para café tostado y molido de acuerdo con el proceso y preparación. (Puerta G. I., 1996).

Se evaluó la calidad de la bebida de café procesado mediante diferentes tipos y condiciones de beneficio, determinándose que el lavado influye favorablemente en la obtención de café calidad suave y ausencia de sabores extraños en la bebida. El tipo de beneficio y en particular, el secado tiene efecto significativo en la calidad de la bebida de café. (Puerta G. I., 1999).

Se produce el mejor café del mundo mediante la recolección manual de los granos de café rojo, las civetas alimentadas con esos granos, su posterior digestión, la recogida y lavado de los granos enteros $\mathrm{y}$ 
a medio digerir de las heces. Una taza de Kopi Luwak puede costar 40 dólares y la bolsa de medio kilo llega a venderse entre 100 y 400 dólares. (Maitres y profesionales de la sala de Aragón, 2012).

El presente trabajo propuso la evaluación fisicoquímica y organoléptica de café ( $C$. arabica L.) fermentado con rumen y $S$. cereviciae a diferente temperatura, para potenciar su cualificación organoléptica y fisicoquímica.

\section{MATERIAL Y MÉTODOS}

El proceso investigativo se realizó el distrito de Limabamba en la región Amazonas ubicada a 1230 m.s.n.m; con el objeto de evaluar las características fisicoquímicas y organolépticas de café ( $C$. arabica L.) fermentado con $S$. cerevisiae y rumen a diferente temperatura; el proceso de fermentación fue el fenómeno de intervención, por lo cual se diseñó un experimento bi-factorial (Montgomery, 2004); donde los factores fueron la relación $S$. cerevisiae rumen y los diferentes temperaturas en el proceso de fermentación del café; determinándose es nueve tratamientos dados por todas las combinaciones posibles entre los niveles de los factores

La materia prima se obtuvo del distrito de Limabamba, provincia de Rodríguez de Mendoza, región de Amazonas, La muestra se seleccionó de forma aleatoria simple, constituida por café cerezo con madurez fisiológica total.

La fermentación que fue un tanque agitado donde se controló el ingreso de oxígeno, temperatura; el proceso de beneficiado del café se llevó a cabo de acuerdo a la ejecución de un flujograma; se realizó la caracterización microbiológica del rumen de ganado vacuno, mediante bibliografía.

\section{Beneficio y fermentación de café}

El beneficio del café se realizó en función de un flujograma desarrollado en base a la Norma Técnica Colombiana $\mathrm{n}^{\circ} 3314$, inicia con la cosecha, selección, el despulpado, mediante una despulpadora. La fermentación; en esta operación se adicionó la cantidad de levadura $S$. cerevisiae rumen de ganado a una diferente temperatura según tratamiento, en un tanque agitado, el lavado se realizó para eliminar los residuos del mucilago, mediante el secado a $60^{\circ} \mathrm{C}$ se eliminó el endocarpio, se clasificó y se envasó, se realizará según NTC $n^{\circ}$ 2167 y NTC $^{\circ} 512$

\section{Evaluación fisicoquímica de café despulpado}

Esta evaluación se realizó al inicio y durante todo el proceso de fermentación con la finalidad de terminar la fermentación para poder tener los resultados de $\mathrm{pH}$, sólidos solubles ( ${ }^{\circ}$ Brix), porcentaje de acidez titulable por método de titulación.

Elaboración de café tostado en bebida para la evaluación organoléptica de cada tratamiento por panelistas semientrenados (Según NTC 3566)

Se realizó el tostado a $\operatorname{los} 200^{\circ} \mathrm{C}$ y $240^{\circ} \mathrm{C}$, se tostaron de $100 \mathrm{~g}$ a $300 \mathrm{~g}$ cuidadosamente hasta que la tostión no debe ser mayor a $12 \mathrm{~min}$ ni menor a $5 \mathrm{~min}$. Inmediatamente se tuesta el café, se vacían los granos en la placa perforada y se introduce aire a presión a través de la cama de granos caliente para ser enfriados.

Molienda y preparación de la muestra de ensayo: se realizó el molido inicialmente $50 \mathrm{~g}$ de la muestra y se desechan, posteriormente se muele toda la muestra, la bebida se preparará durante un máximo de 90 min después de molida.

Preparación de la bebida: se colocó en la taza la porción de ensayo, se calienta el agua en el calentador hasta el punto de ebullición, se deja decantar la infusión durante $5 \mathrm{~min}$, se eliminan los residuos de la superficie de la bebida y se deja enfriar la bebida hasta una temperatura no mayor de $55^{\circ} \mathrm{C}$.

\section{Descripción de las características organolépticas}

Se realizó la evaluación sensorial afectiva usando como medida el grado de preferencia para las bebidas elaborados en la presente investigación. La evaluación se efectuará por 15 panelistas tipo consumidor, empleando una prueba de calificación, con una escala hedónica de 6 puntos: 6-Excelente, 5 Muy bueno, 4-Bueno, 3-Desagradable, 2-Muy desagradable y 1-Malo, recomendado por Ureña y Arriego (1999).

\section{Evaluación Fisicoquímica de café tostado en bebida}

Esta evaluación se realizó a tres mejores tratamientos según la evaluación organoléptica, pH, determinación de los sólidos solubles ( ${ }^{\circ}$ Brix), porcentaje de acidez titulable.

\section{Análisis de datos}

Se empleó un experimento factorial $3^{2}$ bajo un diseño completamente al azar para la evaluación fisicoquímica (Montgomery, 1991), mediante la Prueba de Friedman; el factor A fue la relación porcentaje de $S$. cerevisiae - porcentaje de rumen (0\%:0\%; $0 \%: 10 \% ; 1 \%: 10 \%)$ y el factor B fue la temperatura de fermentación $\left(25^{\circ} \mathrm{C}, 30^{\circ} \mathrm{C}\right.$ y $\left.35^{\circ} \mathrm{C}\right)$ 


\section{RESULTADOS}

\subsection{Características fisicoquímicas del café cerezo}

Tabla 1. Características del café cerezo

\begin{tabular}{|c|c|c|c|c|c|}
\hline Muestra & Color & Aroma & $\begin{array}{c}\text { Densidad } \\
\left(\mathbf{k g} / \mathbf{m}^{\mathbf{3}}\right)\end{array}$ & $\begin{array}{c}\text { Sst } \\
\left({ }^{\mathbf{B}} \mathbf{B r i x}\right)\end{array}$ & $\mathbf{p H}$ \\
\hline $\begin{array}{c}\text { Café } \\
\text { cerezo }\end{array}$ & $\begin{array}{c}\text { Rojo } \\
\text { intenso }\end{array}$ & Característico & 590 & 6.8 & 5.6 \\
\hline
\end{tabular}

5.2. Evaluación fisicoquímica de café despulpado durante el proceso de fermentación

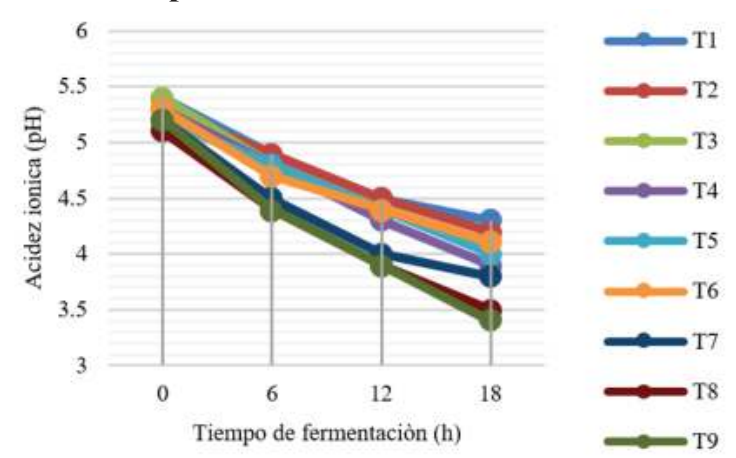

Figura $\mathrm{N}^{\mathrm{o}}$ 1. Valores de acidez iónica $(\mathrm{pH})$ del mucilago de café durante dieciocho horas de fermentación con adición de $30 \%$ de agua.

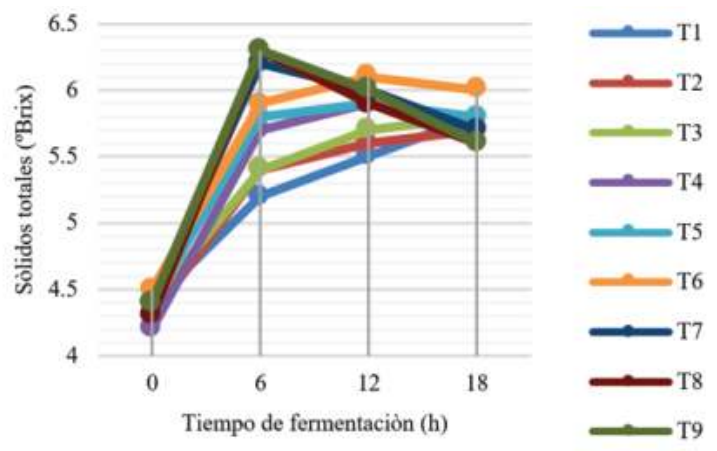

Figura $\mathrm{N}^{\mathrm{o}} 2$. Valores de la concentración de solidos totales ( ${ }^{\circ}$ Brix) del mucilago de café durante dieciocho horas de fermentación con adición de 30\% de agua.

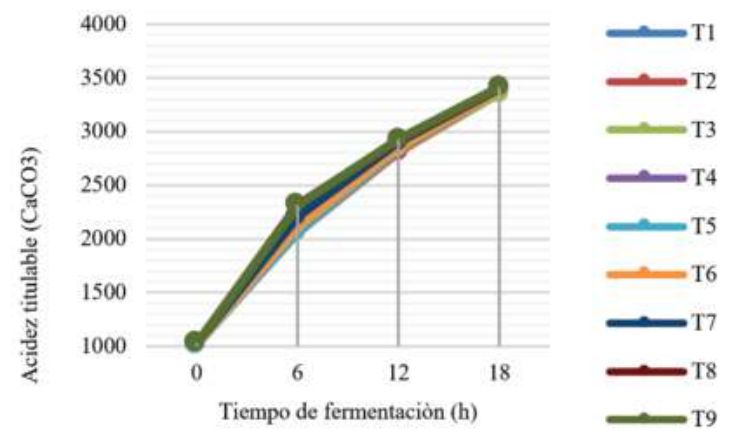

Figura $\mathrm{N}^{\circ} 3$. Valores de la acidificación $\left(\mathrm{mg} \mathrm{CaCO}_{3}\right)$ del mucilago del café durante dieciocho horas de fermentación con adición de $30 \%$ de agua.
Las figuras 1, 2 y 3 muestran el comportamiento del $\mathrm{pH}$, la concentración de solidos totales y la acidez en el proceso de fermentación, importantes para determinar el mejor tiempo de fermentación.

5.3. Evaluación organoléptica de café verde obtenido en cada tratamiento en un tiempo de fermentación de 12 horas

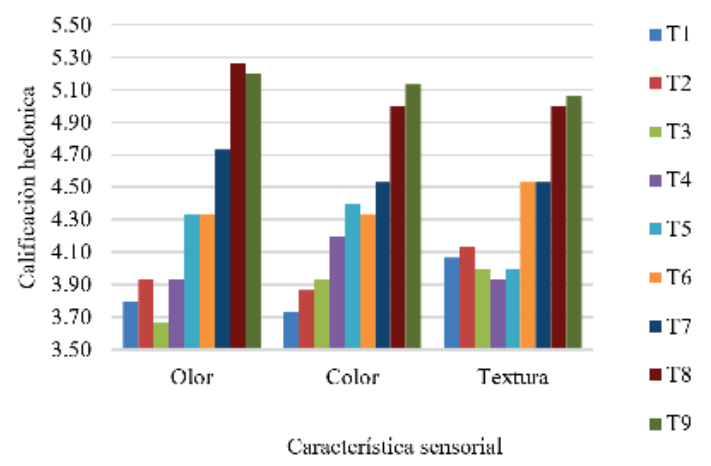

Figura $\mathrm{N}^{\mathrm{o}}$ 4. Calificación hedónica promedio de las características sensoriales del café verde resultado de cada tratamiento secado a $60^{\circ} \mathrm{C}$.

5.1. Evaluación organoléptica de café tostado obtenido en cada tratamiento en un tiempo de fermentación de 12 horas.

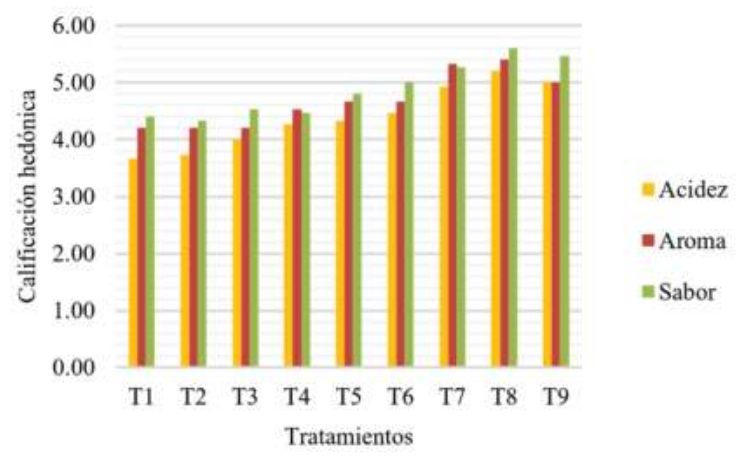

Figura $\mathrm{n}^{\circ} 5$. Calificación hedónica del café tostado en infusión resultado de cada tratamiento realizado por panelistas no entrenados.

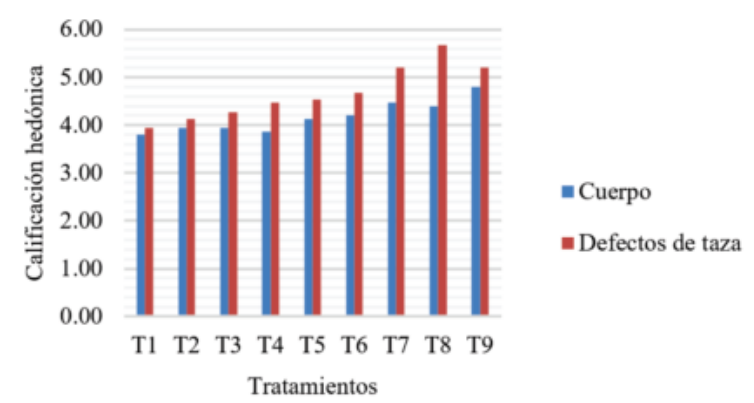

Figura $\mathrm{N}^{\circ}$ 6. Calificación hedónica del café tostado en infusión resultado de cada tratamiento realizado por panelistas no entrenados. 
Las figuras 4, 5 y 6 evidencian que tratamiento el tratamiento 8 (T8); es el mejor según los panelistas no entrenados.

Tabla 2. Valores de la evaluación organoléptica del café tostado en infusión resultado de cada tratamiento realizado por panelistas entrenados.

\begin{tabular}{lcccccccccc}
\hline \multicolumn{1}{c}{ Códigos } & T1 & T2 & T3 & T4 & T5 & T6 & T7 & T8 & T9 & TT \\
\hline Fragancia/aroma & 7.5 & 7.5 & 7.5 & 7.8 & 7.75 & 7.5 & 7.5 & 7.8 & 7.75 & 7.5 \\
Sabor & 7.25 & 7.25 & 7.5 & 7.8 & 7.5 & 7.5 & 7.8 & 7.8 & 7.75 & 7.75 \\
Sabor residual & 7.5 & 7.5 & 7.5 & 7.5 & 7.5 & 7.5 & 7.5 & 7.8 & 7.75 & 7.5 \\
Acidez & 7.5 & 7.5 & 7.5 & 7.5 & 7.5 & 7.8 & 7.5 & 7.8 & 7.5 & 7.5 \\
Cuerpo & 7.5 & 7.5 & 7.75 & 7.5 & 7.5 & 7.5 & 7.5 & 7.8 & 7.75 & 7.75 \\
Balance & 7.5 & 7.5 & 7.5 & 7.5 & 7.5 & 7.8 & 7.8 & 7.8 & 7.75 & 7.75 \\
Uniformidad & 10 & 10 & 10 & 10 & 10 & 10 & 10 & 10 & 10 & 10 \\
Dulzor & 10 & 10 & 10 & 10 & 10 & 10 & 10 & 10 & 10 & 10 \\
Taza limpia & 10 & 10 & 10 & 10 & 10 & 10 & 10 & 10 & 10 & 10 \\
Punt. Catador & 7.5 & 7.5 & 7.5 & 7.5 & 7.5 & 7.5 & 7.5 & 7.5 & 7.5 & 7.5 \\
\hline Total & $\mathbf{8 2 . 2 5}$ & & $\mathbf{8 2 . 7 5}$ & $\mathbf{8 3}$ & $\mathbf{8 2 . 7 5}$ & $\mathbf{8 3}$ & $\mathbf{8 3}$ & $\mathbf{8 4}$ & $\mathbf{8 3 . 7 5}$ & $\mathbf{8 3 . 2 5}$
\end{tabular}

\section{Perfiles:}

T1: Fragancia a vainilla, con un toque de cereal, cuerpo suave y balance medio

T2: Leve cereal, aterciopelado, plano, leve metal

T3: Notas herbales, cuerpo y final áspero

T4: Notas de cereza madura con miel y un final medio

T5: Frutos secos, chocolate, acidez málica con un balance medio

T6: Cáscara panela y un final corto con notas a cereal

T7: Afrutado, durazno, vainilla, con un toque cereal, cuerpo suave y balance medio

T8: Mucha caña, frutos secos, ciruelas, manzana roja, frambuesa

T9: Melaza floral, frutal, acidez a mandarina

En la tabla 2, se muestra la evaluación efectuada por panelistas entrenados a cada tipo de café, obtenido en cada tratamiento en un tiempo de fermentación de 12 horas; asimismo se recomienda la calificación de perfiles estableciéndose en concordancia a la evaluación organoléptica por panelistas no entrenados el tratamiento 8 como el mejor con el perfil indicado.

\begin{tabular}{ccccccccc}
\hline Muestra & $\begin{array}{c}\text { Humedad } \\
(\%)\end{array}$ & $\begin{array}{c}\text { Ceniza } \\
(\%)\end{array}$ & $\begin{array}{c}\text { Extracto } \\
\text { etéreo }\end{array}$ & $\begin{array}{c}\text { Fibra } \\
\text { cruda }\end{array}$ & Proteína & $\begin{array}{c}\text { Extracto } \\
\text { libre de } \\
\text { nitrógeno }\end{array}$ & $\begin{array}{c}\text { pH } \\
(\%)\end{array}$ & $\begin{array}{c}\text { Energía } \\
\text { bruta }\end{array}$ \\
\hline $\mathrm{T} 1$ & 3.812 & 3.498 & 6.654 & 20.35 & 16.38 & 49.404 & 4.91 & 5.677 \\
$(\%)$ & & \\
$(\mathrm{kJ} / \mathrm{kg})$
\end{tabular}

La tabla 3, muestra la evaluación química del café obtenido en el tratamiento 8 (T8); en comparación al tratamiento testigo (TT); donde se resalta el $\mathrm{pH}$ con 5.02 para el tratamiento 8 , lo que indica menor acidez en comparación al testigo.

\section{DISCUSIÓN}

El tiempo de fermentación depende de factores como la altitud; por ejemplo Unión Juárez entre otras ciudades, se ubica a N $15^{\circ} 03^{\prime} 42^{\prime \prime}$ - O 92 $05^{\circ} 40^{\prime \prime}$; que se encuentra a 1230 m.s.n.m. el tiempo de fermentación es 28 h; (Fischersworring y Robkamp, 2001; citado por Caballero y Cruz; 2015); en la presente investigación la fermentación ocurrió en el distrito de Limabamba, en la provincia de Rodríguez de Mendoza; región Amazonas; que se encuentra a una altitud de $1656 \mathrm{msnm}$; latitud de $06^{\circ} 30^{\prime} 35^{\prime \prime}$ sur; longitud 77\%30'35" Oeste; el tiempo de fermentación fue establecido como constante $18 \mathrm{~h}$, de acuerdo a las experiencias de los productores de la zona; sin embargo al realizar los tratamientos se tuvo que detener la fermentación alrededor de las 12 horas teniendo en cuenta que el descenso del pH fue muy acelerado ocurrió principalmente en los tratamientos T7, T8 y T9 (Figura 1); demostrándose que no solo depende de la ubicación el tiempo de fermentación sino también del medio de fermentación y de los agentes que son los microrganismos.

Durante el proceso de fermentación de café, se observa la disminución de 6 a 3 en el pH del mucilago de la masa de granos. Esto debido a que las levaduras; presentes naturalmente en el mucilago, transforman los azucares como la glucosa, fructuosa y sacarosa, otras sustancias orgánicas más simples como etanol, ácido láctico y ácido acético (Puerta G. I., 2010); en la investigación de acuerdo a los resultados se observa que ocurre el descenso del $\mathrm{pH}$ a mayor velocidad ya que en las primeras 12 horas ya el $\mathrm{pH}$ registra valores menores de 4; lo cual podría deberse a la adición de $S$. cerevisiae y rumen $(1 \%-10 \%)$; lo cual aceleraría las reacciones químicas en el sustrato.

En el proceso de fermentación se observa un incremento de solidos solubles totales de 2.8 a 6.5 ${ }^{\circ}$ Brix; esto se debe a que durante la degradación del mucilago, las bacterias transforman los compuestos pécticos y azucares en alcoholes y ácidos orgánicos, lo cual incrementa las sustancias disueltas en el exudado producido durante el proceso de fermentación y pueden alcanzar valores hasta de $8 \%$ (Puerta G. I., 2010); lo mencionado en el presente trabajo ocurre de manera similar; sin embargo en los tratamientos donde hay adición de $S$. cerevisiae y rumen; se incrementa en las primeras 12 horas y luego empieza a descender (Figura 3); este fenómeno podría ser debido a la alta concentración de microorganismos que necesitar alimentarse y consumen los azucares y convierten en otras sustancias más simples. 
Se realizó el registro durante 80 horas continuas del comportamiento de algunas variables $\left(\mathrm{pH}, \mathrm{T}^{\mathrm{o}}\right.$ ambiente, $\mathrm{H}^{\circ}$ relativa, grados ${ }^{\circ} \mathrm{Brix}$ ) asociadas al proceso de fermentación de café Coffe arabica y se determinó como el tiempo de fermentación afecta la calidad de la bebida de café; se pudo determinar la disminución de la concentración de $\mathrm{pH}$, ${ }^{\circ}$ Brix en función del tiempo de fermentación e incremento de la calidad entre la hora 50 y 60 pero disminución considerable después de esta hora hasta la 70 presentándose características en taza como: alcohol y hongos hongos (López, y otros, 2015); en la investigación de manera similar se observó el proceso de fermentación; sin embargo se trabajó 18 horas y fue suficiente porque se había adicionado $S$. cerevisiae y rumen; o quizá también tiene que ver la ubicación geográfica; ya que al realizar las pruebas físicas para ver si el café ya no tenía mucilago adherido.

Se identificaron y cuantificaron las bacterias y levaduras del mucílago de Coffea arabica, fresco y fermentado hasta por 74 horas, a temperatura ambiente y en sistemas abiertos. Se hallaron bacterias $y$ levaduras; los mayores recuentos se encontraron en el mucílago de café obtenido de frutos maduros y granos seleccionados. (Puerta, Marín, \& Osorio, 2012); en contraste a lo mencionado en la presente investigación se trabajó una experiencia en campo, donde la principal condición fue evaluar las características fisicoquímicas y sensoriales del café fermentado, con adición de $S$. cerevisiae y rumen; $\sin$ embargo se infiere que la flora microbiana en el proceso fue en mayor cantidad y fue por eso la aceleración en el descenso del pH, en algunos tratamientos.

Se determinó que debido a condiciones del suelo el café evaluado inicio con un $\mathrm{pH}$ neutro frente a las muestras evaluadas por Cenicafé esto explica el incremento en el tiempo de fermentación, por otro lado se logró determinar el tiempo de duración del proceso para situar el café en un $\mathrm{pH}$ ideal de 3,5 teniendo en cuenta una temperatura ambiente de $20^{\circ}$ $\mathrm{C}$ y una altura que oscila entre los $1.470-1.500$ metros sobre el nivel del mar. (Cárdenas \& Pardo, 2014); En ese sentido en el presente trabajo se inició con un $\mathrm{pH}$ de 5.5 aproximadamente y se finalizó a un pH de 3.5 y ello sucedió a las 18 horas para los tratamientos (T1, T2, T3, T4,T5, T6) y a las 12 horas para los tratamientos (T7, T8, T9); sabiendo que el lugar donde se fermentó el café estuvo a 1230 m.s.n.m; y la temperatura optima según los resultados fue $30^{\circ} \mathrm{C}$; de esta forma se puede inferir que se aceleró la fermentación por las condiciones como la concentración de flora microbiana y el manejo de la temperatura.
Se demostró que a partir de un 2,5\% de café cosechado verde, ya sea procesado por desmucilaginado mecánico o por fermentación natural, se rechazan desde el $30 \%$ de las tazas por defectos. (Puerta G. I., 2000); en la investigación no existió rechazo al café en bebida, porque el proceso tecnológico fue riguroso y fue en menor cantidad, lo cual permitió mayor control.

Se evaluó la calidad de la bebida de café procesado mediante diferentes tipos y condiciones de beneficio. En el proceso de beneficio húmedo, lavado con agua limpia y secado inmediato se produjo café suave de mejor calidad, en comparación con los otros tipos y condiciones de proceso. (Puerta G. I., 1999); En la investigación se utilizó de forma similar el beneficio húmedo, lo que en total se terminó adicionando un $30 \%$ de agua; sin embargo el secado se realizó de manera lenta con exposición a los rayos solares; situación que podría modificar características aromáticas o sustancias termolábiles.

\section{CONCLUSIONES}

Se evaluó las características fisicoquímicas y organolépticas de café (C. arabica L.) fermentado con rumen y $S$. cereviciae a diferente temperatura determinándose según la prueba de Friedman; la obtención de café caracterizado con perfil organoléptico "Mucha caña, frutos secos, ciruelas, manzana roja, frambuesa" y calificación hedónica "Muy bueno", para aroma, sabor, acidez, textura, cuerpo y defectos de taza; obtenido en un tiempo de fermentación de 12 horas; a $30^{\circ} \mathrm{C}$, con adición de $1 \%$ de levadura $-10 \%$ de rumen de ganado vacuno (T8) a una altitud de 1230 m.s.n.m.

El tiempo de fermentación disminuye a 12 horas, en comparación las aproximadamente 80 horas de manejo tradicional; validándose también con la evaluación fisicoquímica del tratamiento (T8) y el tratamiento testigo (T1); donde se demuestra datos el $\mathrm{pH}$ de 5.02 frente al testigo que fue 4.92. demostrándose así la baja acidez del café obtenido.

\section{REFERENCIAS}

AOAC. (1990). Association of Official Analytical Chemists. Official Methods of Analysis of the.AOAC. Washington, USA. 15 th edition.

Agrobanco. (2007). Cultivo del café. Lima, Perú. Obtenido dewww.agrobanco.com.pe/data/uploads/ctecnica/0 39-a-tropicales.pdf

Arcos, C. A. (2017). Monografía: Efecto de la 
fermentación aerobia del grano despulpado de café orgánico, en el desarrollo de características sensoriales de la bebida en el Municipio de Pitalito. Huila - Colombia: Universidad Nacional Abierta y a Distancia; Escuela de Ciencias Básicas Tecnología e Ingeniería;

Caballero, J. F., \& Cruz, F. J. (Setiembre de 2015). La fermentación y el secado del café. Chiapas, México: Instituto nacional de investigaciones forestales, agricolas y pecuarias; Centro de investigación regional pacífico sur; .

Cárdenas, J. P., \& Pardo, J. D. (2014). Caracterización de las etapas de fermentación y secado del café la primavera. Bogota D.C: Escuela colombiana de Ingeniería Julio Garavito; Programa de Ingeniería industrial

Cheftel.J \& Cheftel.(1977). Introducción a la bioquímica y tecnología de Alimentos. Zaragoza España, Editorial. Acribia.

Church, D. C. (1974). Fisiología digestiva y nutrición de los rumiantes. Editorial Acribia. Zaragoza, España. Federación Nacional de Cafeteros. Disponible en: http://www.cafedecolombia.com/particulares/es/el_ cafe_de_colombia/un_cafe_sobresalient

Desco, \& Programa selva central. (2012). Producción de cafes especiales - Manual técnico. Herramientas para el desarrollo, 46. Lima, Perú: Centro de estudios y promoción del desarrollo.

Fellows, P. (1994). Tecnología del procesado de los alimentos: Principios y práctica . Zaragoza - España: Editorial Acribia.

Finney, J. (1985). Diseño y Análisis de Experimentos. México. Grupo Editorial Ibero América.

Goode, W. J., \& Hatt, P. K. (1986). Métodos de Investigación Social (Décima cuarta edic. ed.). México: Ed. Trilla.

Inei. (2013). IV Censo nacional agropecuario 2012. Lima Perú: Instituto nacional de estadística e informática Ministerio de agricultura y riego.

Inei. (mayo de 2017). Producción de café creció 21,4\% en marzo de 2017. Nota de prensa. Lima, Perú: Instituto nacional de estadistica e informática.

López, C. F., Rojas, P. A., Montaña, L. O., Tovar, E. S., Rojas, Y., Arcos, C. A., . . . Vega, G. A. (2015). Estudio de algunas variables en el proceso de fermentación del café y su relación con a calidad de taza en el sur de Colombia. Agroecología: ciencia y tecnología, 3(1), 7-12.

Maitres y profesionales de la sala de Aragón . (04 de abril de 2012). Del cafetal a tu taza. Obtenido de Kopi Luwak. El café más caro del mundo: http://archivo.maitresdearagon.com/es/index.php?o ption $=$ com_content\&view $=$ article $\& i d=1151 \&$ Itemi $\mathrm{d}=137$

Marín, S. M., Arcila, J., Montoya, E. C., \& Oliveros, C. E.
(2003). Relación entre el estado de madurez del fruto del café y las características del beneficio, rendimiento y calidad de la bebida. Cenicafé, $297-$ 315.

Minagri. (2013). Situación del mercado del café en grano. Lima - Perú: Oficina de Estudios Económicos y Estadísticos - OEEE - Ministerio de agricultura y riego.

Misti. (2017). Cultivo de café. Lima: Misti- Fertilizantes crecen tus cultivos y tu también. Recuperado el 7 de enerode2018,dehttp://infocafes.com/descargas/bibli oteca/349.pdf

Montgomery, D. C. (2004). Diseño y análisis de experimentos. México: Limusa S.A. Wiley.

Puerta, G. I. (1996). Escala para la evaluación de la calidad de la bebida de café verde Coffea arabica, procesado por vía húmeda. Cenicafé, 231-234.

Puerta, G. I. (1999). Influencia del proceso de beneficio en la calidad del café. Cenicafé, 78 - 88.

Puerta, G. I. (2000). Calidad en taza de algunas mezclas de variedades de café de la especie Coffea arabica L. Cenicafé, 5-19.

Puerta, G. I. (2000). Influencia de los granos de café cosechados verdes, en la calidad física y organoléptica de la bebida. Cenicafé, 136 - 150.

Puerta, G. I. (2006). La humedad controlada del grano preserva la calidad del café. Avances técnicos cenifafé, 352, 1-8.

Puerta, G. I. (2010). Fundamentos del proceso de fermentación en el beneficio del café. Chinchiná : Cenicafé (Avances técnicos), 12.

Puerta, G. I. (2011). Composición química de una taza de café. Avances técnicos cenicafé, 12.

Puerta, G. I. (2012). Factores, procesos y controles en la fermentación del café . Chinchiná : Cenicafé (Avances Técnicos No. 422), 12.

Puerta, G. I. (2013). Cinética química de la fermentación del mucilago de café a temperatura ambiente. Revista Cenicafé, 64(1), 42 - 59.

Puerta, G. I. (2015). Fermentación controlada del café: Tecnología para agregar valor a la calidad. Avances técnicos Cenicafé, 12.

Puerta, G. I., Marín, J., \& Osorio, G. A. (2012). Microbiología de la fermentación del mucílago de cafés según su madurez y selección. Revista Cenicafé, 63(2), $58-78$

Queirolo, C. (2010). Promoción del consumo interno de café en el Perú : Lineamientos de estrategia. Lima Perú: Escuela de post grado - Pontificia Universidad Católica del Perú.

Ureña, M \& Arriego, M. (1999). Evaluación sensorial de los alimentos, aplicación didáctica. Facultad de industrias alimentarias. Universidad Nacional 
Agraria La Molina. Lima-Perú

Van Lie, E., \& Regueiro, M. (2008). Digestión en retículo rumen. Montevideo - Uruguay: Universidad de la republica - Facultad de agronomía.

Witting de Penna, E. (2001). Evaluación sensorial. Una metodología actual para tecnología de alimentos. Santiago de Chile. 125 pp.

Zambrano, D. A., \& Isaza, J. D. (1998). Demanda química de oxígeno y nitrógeno total, de los subproductos del proceso tradicional de beneficio húmedo del café. Cenicafé, 279-289. 